\title{
Power Flow Simulation for Two-Degree-of-Freedom Planetary Gear Transmissions with Experimental Validation
}

\author{
Hamed Ali Hussen $\mathbb{D}^{1},{ }^{1}$ Essam Lauibi Esmail $\mathbb{D}^{2}{ }^{2}$ and Rahman A. Hussen $\mathbb{D}^{1}$ \\ ${ }^{1}$ Middle Technical University, Baghdad, Iraq \\ ${ }^{2}$ University of Al-Qadisiyah, Al Diwaniyah 0964, Iraq \\ Correspondence should be addressed to Essam Lauibi Esmail; dr.essamesmail@yahoo.com
}

Received 16 August 2020; Revised 7 October 2020; Accepted 12 October 2020; Published 7 November 2020

Academic Editor: Mohamed B. Trabia

Copyright (c) 2020 Hamed Ali Hussen et al. This is an open access article distributed under the Creative Commons Attribution License, which permits unrestricted use, distribution, and reproduction in any medium, provided the original work is properly cited.

\begin{abstract}
The basic relationships among gear ratios, velocity succession, torque directions, power ratios, energy losses, and efficiency are derived from first principles. The techniques presented here can be applied to ordinary, planetary, or mixed gear trains. Also, these techniques provide more insight into how power is flowing through the different parts of the mechanism. Power flow relationships are a helpful tool to study power amplification and power circulation in multipath transmissions. They also provide more insight into how the gear pair entities (GPEs) or gear train entities (GTEs) affect total power losses and allow immediate derivation of the overall efficiency. A representative two-input mechanism is analyzed to demonstrate the effectiveness of improved techniques. The theoretical results are compared with experimental data of previous work. The theoretical and experimental curves exhibit identical trends with a distinct jump in friction loss. The jump is explained by a change in the way of the power flow through the mechanism. The conditions under which power circulation occurs are determined. The results have important implications for understanding how to improve the efficiency of multipath power flow systems.
\end{abstract}

\section{Introduction}

Planetary gears are widely used in various industrial fields [1-9]. Predetermining power recirculation in the early stage of the design of planetary gear trains is important to avoid the operating condition, which may result in excessive power losses [10-12], power amplification [10, 13, 14], or power recirculation [15-17]. The main causes of power losses in planetary gear trains are due to tooth friction, oil churning, and friction in bearings [12]. In this study, only the power losses resulting from sliding friction of gears will be considered.

The previous methods for calculating the efficiency of PGTs can be classified into two main categories; the first one depends on the torque balance of the system [18-23], while the second relies on the concept of potential [24, 25] (latent [26] and virtual [27-30]) power. The potential power is the power corresponding to the relative power $P_{i}^{j}=T_{i}\left(\omega_{i}-\omega_{j}\right)$ transmitted through link $i$ in a MRF in which link $j$ seems to be relatively fixed. The concept of potential power is a powerful tool for analyzing the power flow and efficiency of PGTs.

$\mathrm{Yu}$ and Beachley [26] introduced the term "latent power" to denote the power measured by an observer moving with the planet carrier. Chen and Angeles [27] defined the power measured in an arbitrary MRF as the "virtual power." However, the "virtual power" was used only in the sense of the "latent power," the power that passes through the gear train at the carrier MRF. The virtual power is used to compute the power loss of PGTs [27-30]. In all previous works, the planet carrier was chosen as the observer's reference frame. In such a frame, a single-planet carrier PGT appears as an OGTE and the evaluation of power losses is greatly simplified. However, when dealing with multicarrier PGTs, the approach in [30] is in big trouble. The main reason is that the carriers of a compound planetary gear train cannot all 
brought to rest at the same time. The approach, which was thought to simplify the solution, led to contradictions in analysis and became a reason for the solution complexity. Esmail [31] also argued that the virtual power method is controversial and there is no general agreement on its reliability. Verbelena et al. [32] used the method of Chen and Angeles [27] to estimate the impact of different formulations on the total gear train efficiency. The calculated planetary gear efficiency is then compared with the measurements to determine what level of accuracy is required. Wang [33] implemented an optimization method for high power density taking into account volume and efficiency. The power loss of the optimized system is reduced by $11.42 \%$, and the system size is reduced by $25.2 \%$. Both Verbelena et al. [32] and Wang [33] used a single-carrier planetary gear train. A PGT that contains a single-planet carrier is called a GTE, whereas a compound PGT (or simply a PGT) is a union of several GTEs.

For multicarrier compound systems, we introduce a new approach based on the concepts of GPEs, GTEs, and their bridge links. Based on these concepts, a compound PGT is analyzed. For any three links of a general multipath gear train entity, an equation describing the amount of power transmitted among these three links is derived. Since the equation contains only velocity ratios and local efficiencies, there is no need for torque analysis to evaluate these powers. Macmillan [14] obtained a similar expression for the power flowing through a differential transmission. Pennestri and Freudenstein [10] also proposed a similar equation but in the absence of friction loss. In this work, we will focus on the power losses in two-DOF PGTs. In many applications, PGTs with two degrees of freedom are basic trains [5-9]. The two-input compound PGT, shown in Figure 1, has been patented by NASA, as described in their earlier known Reference [34]. This patent is descriptive in nature. Pennestri and Freudenstein [10] discussed the power flow analysis of the same PGT. However, their analysis does not take into account power losses, nor does it address the efficiency of the train and the factors influencing it.

One of the works closely related to the work studied in this paper is the experimental work presented in [35], where lubricants are not used on tooth surfaces. These recent experiments showed that "the mechanical efficiency may be reduced to a value less than 0.33 , which is usually much lower than the efficiency of a simple gear train" [36]. Chen and Chen [35] "attributed the efficiency jump in the efficiency map, when the input torque is increased to the different local loss factors induced at gear meshes with different loads." However, these authors do not provide any explanation as to how the local loss factor may change with load. The current author believes that the reason may be due to not following an appropriate approach that fits correctly with the experimental results. In this regard, the question to be asked is whether it is possible to obtain local efficiencies experimentally, to use them in the theoretical equations. In this paper, a method is elaborated to calculate the local efficiency of the OGTE $\left(\eta_{3}\right)$ and the coupled efficiency of the PGTE $\left(\eta_{1} \eta_{2}\right)$ from experimental data taken from the study of Chen and Chen [35] and use them in the theoretical expressions of the power losses and total effi-

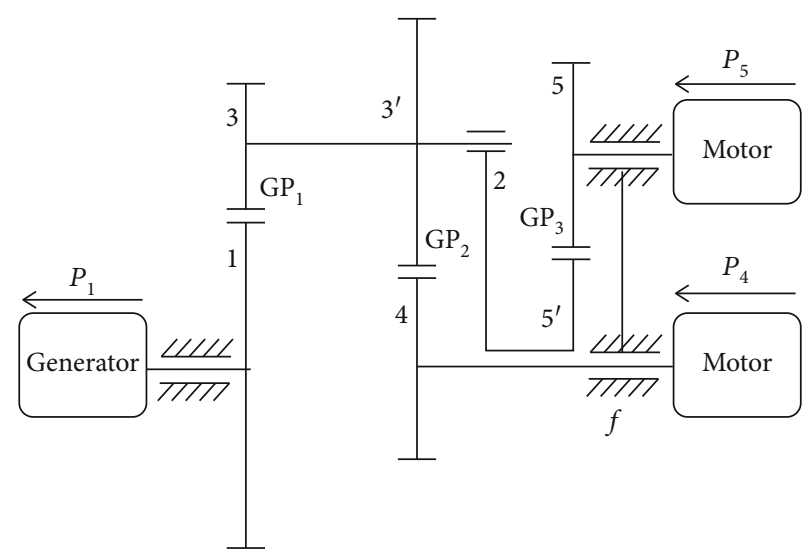

FIGURE 1: A PGT having 2 inputs and 1 output.

ciency of the system. References [16, 25, 28, 29, 35-39] contain a review of the known efficiency equations of the two-degreeof-freedom systems. For the simplified model of the two-DOF system shown in Figure 2, Chen and Chen [35] obtained similar efficiency formulas to those of Maggiore [38] and Monastero [39] but in a different way. For the same simple PGT, Esmail [36] recently studied the effect of operating conditions on tooth loss. The simplified PGT shown in Figure 2 is the planetary part of the compound PGT shown in Figure 1. In all previous works, the influence of external operating conditions on power losses is not taken into account, neither in the simplified PGT shown in Figure 2 nor in the compound PGT shown in Figure 1.

The mechanism shown in Figure 1 consists of two entities: a PGT entity (PGTE) containing links $1,2,3,3^{\prime}$, and 4 and an OGT entity (OGTE) containing links 5 and $5^{\prime}$. The OGTE can be considered as a PGTE with a fixed planet carrier. In the PGTE, there are two external gear pair entities (GPEs): GPE1 containing gears 1 and 3 and carrier 2 and GPE2 containing gears 4 and $3^{\prime}$ and carrier 2, while the OGTE contains only GPE3 which is formed from gears 5 and $5^{\prime}$ and the fixed-to-ground carrier $f$.

\section{Velocity Ratio Analysis}

For any compound planetary gear train consisting of two or more GPEs and/or GTEs, the "velocity ratio" $R_{i, j}^{k}$ between two links ( $i$ and $j$ ) of a PGT with respect to a third link $(k)$ is written as the following [40]:

$$
R_{i, j}^{k}=\frac{R_{i, b 1}^{b 2}-R_{k, b 1}^{b 2}}{R_{j, b 1}^{b 2}-R_{k, b 1}^{b 2}}=\frac{\omega_{i}-\omega_{k}}{\omega_{j}-\omega_{k}},
$$

where links $i, j$, and $k$ belong to different GPEs and/or GTEs and $b_{1}$ and $b_{2}$ are the common links between them.

When the links $w, u$, and $v$ belong to the same GTE and because the links $p$ and $c$ are common links in the GTE, Equation (1) can be written as follows:

$$
R_{w, u}^{v}=\frac{R_{w, p}^{c}-R_{v, p}^{c}}{R_{u, p}^{c}-R_{v, p}^{c}}=\frac{\omega_{w}-\omega_{v}}{\omega_{u}-\omega_{v}} .
$$




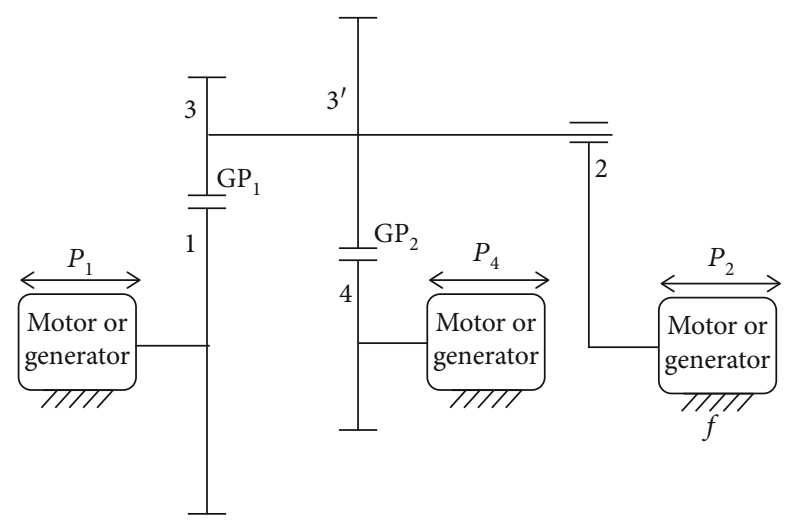

Figure 2: The two-DOF PGT.

The distinctive elements of the GPE are the gears $q$ and $p$ and the carrier $c$. GPEs are the building blocks of GTEs and/or PGTs. For velocity and power flow analysis, the GPE is represented as in Figure 3.

From Equation (2) and for any GPE, $R_{q, p}^{c}$ can be written as

$$
R_{q, p}^{c}=\frac{R_{q, p}^{c}-R_{c, p}^{c}}{R_{p, p}^{c}-R_{c, p}^{c}}=\frac{\omega_{q}-\omega_{c}}{\omega_{p}-\omega_{c}},
$$

where $R_{c, p}^{c}=0$ and $R_{p, p}^{c}=1$.

$R_{q, p}^{c}$ can be written in terms of the number of teeth of the mating gears $Z_{p}$ and $Z_{q}$ as

$$
R_{q, p}^{c}=\mp \frac{Z_{p}}{Z_{q}},
$$

with the minus (plus) sign for external gears (internal gears).

\section{Identification of the Input Link in the MRF}

The carrier potential power ratio is defined as the ratio between $T_{i}\left(\omega_{i}-\omega_{c}\right)$ and $T_{i} \omega_{i}$,

$$
\frac{P_{i}^{c}}{P_{i}}=\frac{T_{i}\left(\omega_{i}-\omega_{c}\right)}{T_{i} \omega_{i}}=\frac{\left(\omega_{i}-\omega_{c}\right)}{\omega_{i}-\omega_{f}}=R_{c, f}^{i},
$$

where $\left(\omega_{f}=0\right)$.

$$
P_{i}^{c}=R_{c, f}^{i} P_{i}
$$

where $i$ is a link other than the planet carrier $c$ with a known power, i.e., either an input or output link or a link having a power that can be calculated in terms of them. An input link in the FRF does not necessarily have the same role in the MRF. Generally, the ratio $R_{c, f}^{i}$ can be determined from the kinematic analysis of the train. If the $P_{i}$ sign is known, from Equation (6), the sign of $P_{i}^{c}$ can be easily determined.

In the MRF:

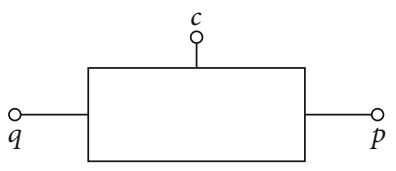

FIgURE 3: Schematic diagram of a gear pair entity.

(a) When $P_{i}^{c}>0$, link $i$ must be a driving link in the MRF and will be given the symbol $x$

(b) When $P_{i}^{c}<0$, link $i$ must be a driven link in the MRF and will be given the symbol $y$

The friction losses $(l)$ contributed by any planetary gear train entity are obtained as a product of $P_{x}^{c}$ and $\left(=\eta_{c}-1\right)$. That is,

$$
l=\left(\eta_{c}-1\right) P_{x}^{c} .
$$

\section{Power-Flow Ratios in GTEs and/or GPEs}

In MRF, when link $z$ is relatively fixed, the $\eta_{z(x-y)}$ is given by

$$
\eta_{z(x-y)}=-\frac{T_{y}}{T_{x}} R_{y, x}^{z}
$$

Multiplying both sides of Equation (8) by $R_{y, x}^{f}\left(=\omega_{y} / \omega_{x}\right)$ and rearrange, we get

$$
\frac{P_{y}}{P_{x}}=-\frac{\eta_{z(x-y)}}{R_{y, x}^{z} R_{x, y}^{f}} .
$$

From Equation (8),

$$
\frac{T_{y}}{T_{x}}=-\frac{\eta_{z(x-y)}}{R_{y, x}^{z}} .
$$

But

$$
\frac{T_{z}}{T_{x}}=-1-\frac{T_{y}}{T_{x}} .
$$

Substitute Equation (10) into Equation (11), we get

$$
\frac{T_{z}}{T_{x}}=\frac{\eta_{z(x-y)}}{R_{y, x}^{z}}-1 .
$$

Multiplying both sides of Equation (12) by $R_{z, x}^{f}\left(=\omega_{z} / \omega_{x}\right)$ and rearrange, we get

$$
\frac{P_{z}}{P_{x}}=\left(\frac{\eta_{z(x-y)}}{R_{y, x}^{z}}-1\right) R_{z, x}^{f} .
$$

Equations (5), (9), and (13) yield the power ratios in GPE 
and/or GTE. These equations can be summarized as follows:

$$
\frac{P_{x}}{R_{y, x}^{z}}=-\frac{P_{y}}{\eta_{z(x-y)} R_{y, x}^{f}}=\frac{P_{z}}{\left(\eta_{z(x-y)}-R_{y, x}^{z}\right) R_{z, x}^{f}}=\frac{P_{x}^{z}}{R_{y, x}^{z} R_{z, f}^{x}} .
$$

If one of the links $(x, y$, or $z)$ of the entity is stationary, only the mathematic expressions that do not contain the subscript denoting the stationary link are used.

\section{Torque Ratios in GTEs and/or GPEs}

For any three links $x, y$, and $z$ of a GTE with their velocities arranged in the following ascending or descending order: $\omega_{x}: \omega_{y}: \omega_{z}$, we can deduce the directions of torques from Equations (8) and (10). Using the same method used to derive Equations (8) and (10), $\eta_{y(x-z)}$ and $T_{z} / T_{x}$ can be obtained in a similar form:

$$
\eta_{y(x-z)}=-\frac{T_{z}\left(\omega_{z}-\omega_{y}\right)}{T_{x}\left(\omega_{x}-\omega_{y}\right)}=-\frac{T_{z}}{T_{x}} R_{z, x}^{y}
$$

From Equation (15),

$$
\frac{T_{z}}{T_{x}}=-\frac{\eta_{y(x-z)}}{R_{z, x}^{y}} .
$$

The velocity ratio $R_{y, x}^{z}$ can be written from Equation (1) as $R_{y, x}^{z}=\left(\omega_{y}-\omega_{z}\right) /\left(\omega_{x}-\omega_{z}\right)$. Since the velocities are arranged in the sequence $\omega_{x}: \omega_{y}: \omega_{z}$, the relative velocities $\left(\omega_{y}-\omega_{z}\right)$ and $\left(\omega_{x}-\omega_{z}\right)$ always have the same sign, either positive or negative, and therefore, $R_{y, x}^{z}>0$. Moreover, $R_{z, x}^{y}$ $=\left(\omega_{z}-\omega_{y}\right) /\left(\omega_{x}-\omega_{y}\right)$, where $\left(\omega_{z}-\omega_{y}\right)$ and $\left(\omega_{x}-\omega_{y}\right)$ have always opposite signs. Therefore, $R_{z, x}^{y}<0$.

By returning to Equations (8) (or (15)) and (10) (or (16)), since efficiency is always positive, and $R_{y, x}^{z}>0$ and $R_{z, x}^{y}<0$, therefore, we can deduce that

$$
\begin{aligned}
& \frac{T_{y}}{T_{x}}=-\frac{\eta_{z(x-y)}}{R_{y, x}^{z}}<0, \\
& \frac{T_{z}}{T_{x}}=-\frac{\eta_{y(x-z)}}{R_{z, x}^{y}}>0 .
\end{aligned}
$$

Since $T_{z} / T_{x}>0$, and $T_{y} / T_{x}<0$, therefore, $T_{x}$ and $T_{z}$ must have the same direction, while $T_{x}$ and $T_{y}$ must have opposite directions.

Despite similarities, it may be better to highlight the difference between this work and others. It is appropriate to emphasize that the main steps in the methodology, such as the torque direction, have not been discussed in the papers of other authors nor in the present author's previous works. The novel result of this section can be summed up as follows: "for any three links $x, y$, and $z$ of a GTE with their velocities arranged in the following ascending or descending order: $\omega_{x}: \omega_{y}: \omega_{z}, T_{x}$ and $T_{z}$ must have the same direction while the direction of $T_{y}$ must be opposite to the direction of $T_{x}$ and $T_{z}$." This important result will facilitate the calculation of the actual power, potential power, and power flow ratio. Added to this is the existence of one equation (Equation (14)) from which all power and potential power ratios in planetary gear train entities (and/or GPEs) can be calculated.

\section{Velocity Sequence}

For any internal gear pair and by using Equations (3) and (4), we can write $R_{q, p}^{c}$ as

$$
R_{q, p}^{c}=\frac{Z_{p}}{Z_{q}}=\frac{\omega_{q}-\omega_{c}}{\omega_{p}-\omega_{c}} .
$$

For any internal gear pair, $Z_{q}$ is larger than $Z_{p}$, which simply means that

$$
0<\frac{Z_{p}}{Z_{q}}=\frac{\omega_{q}-\omega_{c}}{\omega_{p}-\omega_{c}}<1
$$

Equation (19) implies that both $\left(\omega_{q}-\omega_{c}\right)$ and $\left(\omega_{p}-\omega_{c}\right)$ are either positive or negative. If $0<\left(\omega_{q}-\omega_{c}\right)$ and $0<\left(\omega_{p}\right.$ $\left.-\omega_{c}\right)$, then from Equation (19), $\left(\omega_{q}-\omega_{c}\right)<\left(\omega_{p}-\omega_{c}\right)$ which implies that $\omega_{c}<\omega_{q}, \omega_{c}<\omega_{p}$, and $\omega_{q}<\omega_{p}$. This can be written in a compact form as $\omega_{c}<\omega_{q}<\omega_{p}$. Similarly, if $0>\left(\omega_{q}\right.$ $\left.-\omega_{c}\right)$ and $0>\left(\omega_{p}-\omega_{c}\right)$, then from Equation (19), $\left(\omega_{q}-\omega_{c}\right.$ )$>\left(\omega_{p}-\omega_{c}\right)$ which implies that $\omega_{c}>\omega_{q}, \omega_{c}>\omega_{p}$, and $\omega_{q}>$ $\omega_{p}$. This can be written in a compact form as $\omega_{c}>\omega_{q}>\omega_{p}$.

In short, the velocity sequence is

$$
\omega_{c}: \omega_{q}: \omega_{p} \text { when } 0<R_{q, p}^{c}<1 .
$$

In the same way, for external and multiplanet gear pairs, the following can be proven:

$$
\begin{aligned}
& \omega_{q}: \omega_{c}: \omega_{p} \text { when } R_{q, p}^{c}<0, \\
& \omega_{c}: \omega_{p}: \omega_{q} \text { when } 1<R_{q, p}^{c} .
\end{aligned}
$$

In general, when the planetary gear ratios are arranged in the following ascending sequence:

$$
R_{q_{1}, p}^{c}<R_{q_{2}, p}^{c}<\cdots<0<R_{q_{3}, p}^{c}<R_{q_{4}, p}^{c}<\cdots<1<R_{q_{5}, p}^{c}<R_{q_{6}, p}^{c}<\cdots,
$$

the angular velocities occur in the following ascending or descending sequence:

$$
\omega_{q_{1}}: \omega_{q_{2}}: \cdots: \omega_{c}: \omega_{q_{3}}: \omega_{q_{4}}: \cdots: \omega_{p}: \omega_{q_{5}}: \omega_{q_{6}}: \cdots
$$

\section{Application Example}

After explaining the basis of the present methodology for studying power losses and efficiency analysis in planetary 


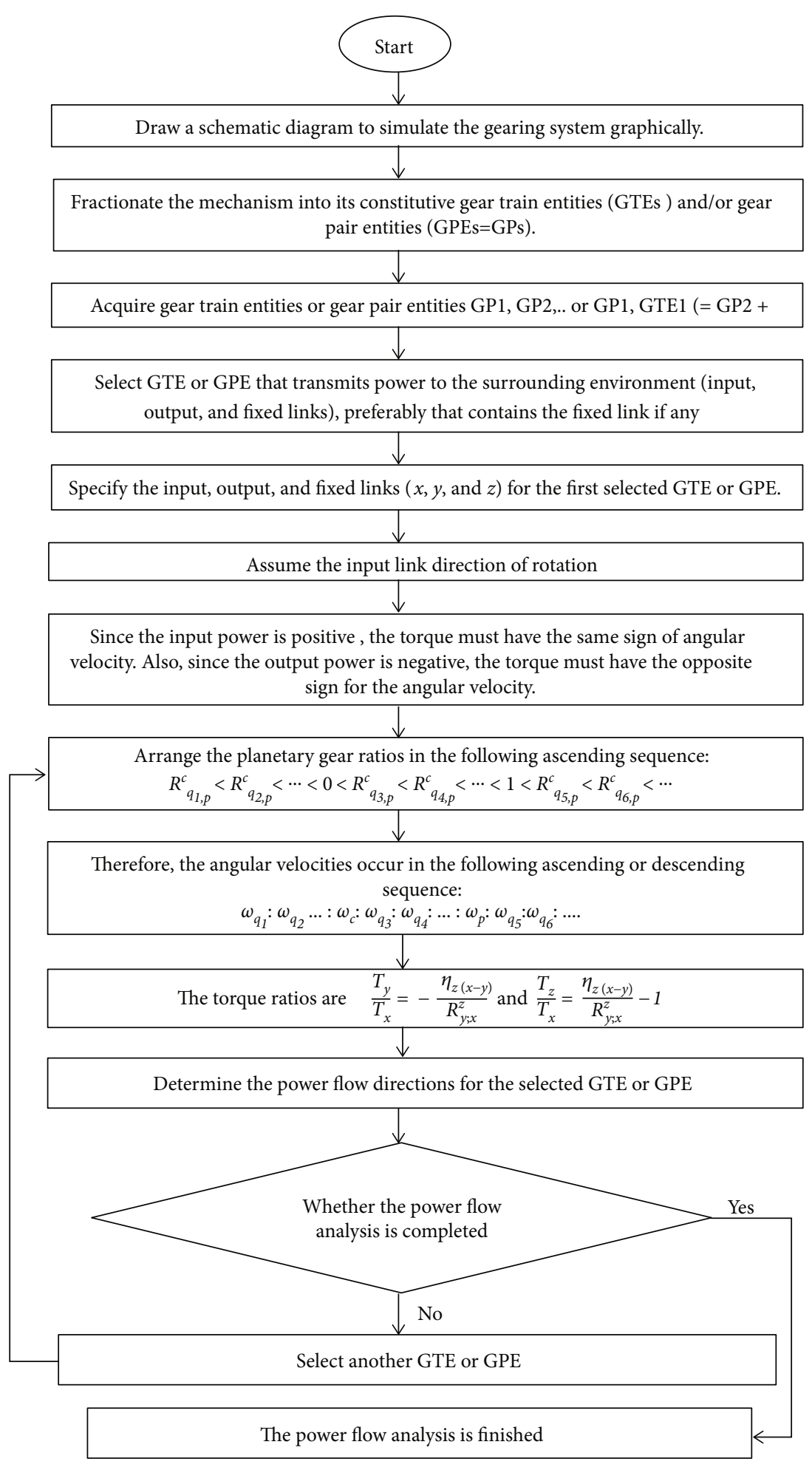

Figure 4

gear trains, it became necessary to apply the proposed procedure to a multi-degree-of-freedom application example.

In the beginning, we must emphasize that the equations derived for power flow ratios and torque ratios in GTEs and/or GPEs do not apply directly to compound PGTs consisting of several GTEs. Such PGTs must first be fractionated into its constitutive gear train entities (GTEs). Common links are used to fractionate PGT into its constitutive gear train entities (GTEs). Common links have the function of transmitting power from one GTE to another. The main steps of the proposed procedure to determine how power is flowing through the different parts of the PGT and the conditions in which power circulation occurs are summarized in the following flow chart and detailed step-by-step as follows: 


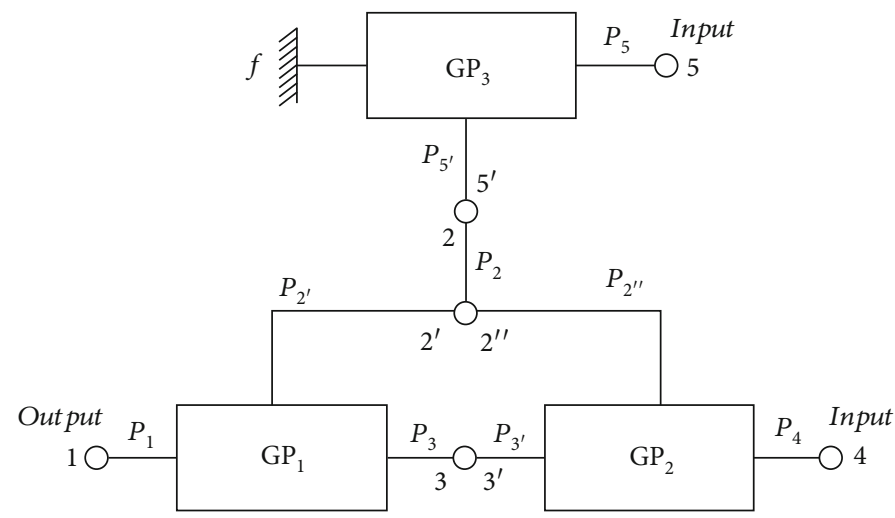

Figure 5: Scheme of the gearing system shown in Figure 1.

Step 1. A schematic diagram is drawn for each gear pair entity (Figure 4). Then, the schematic diagrams of all the gear pair entities of the gearing system are joined to each other through their shared links. Figure 5 illustrates the scheme of the system shown in Figure 1. Input, output, and fixed links in the fixed reference frame are also specified in the diagram.

From Equation (3), the planet gear ratios of the GPEs can be written as the following: for GPE1, $R_{1,3}^{2}=-Z_{3} / Z_{1}$; for GPE2, $R_{4,3^{\prime}}^{2^{\prime}}=-Z_{3^{\prime}} / Z_{4}$; and for GPE3, $R_{5,5^{\prime}}^{f}=-Z_{5^{\prime}} / Z_{5}$. For the planet gear ratios $R_{1,3}^{2}$ and $R_{4,3^{\prime}}^{2^{\prime}}$, there are two cases depending on the number of teeth on the mating gears: either $\left(R_{4,3^{\prime}}^{2^{\prime}} / R_{1,3}^{2}\right)>1$ or $0<\left(R_{4,3^{\prime}}^{2^{\prime}} / R_{1,3}^{2}\right)<1$.

Without loss of generality, suppose that the teeth on the gears are as follows: $Z_{1}=36, Z_{3}=28, Z_{3^{\prime}}=36, Z_{4}=28, Z_{5}$ $=30$, and $Z_{5^{\prime}}=30$. Therefore, $R_{1,3}^{2^{\prime}}=-28 / 36, R_{4,3^{\prime}}^{2^{\prime \prime}}=-36 / 28$, and $R_{5,5^{\prime}}^{f}=-1$ and $\left(R_{4,3^{\prime}}^{2^{\prime}} / R_{1,3}^{2}\right)>1$.

Step 2. The common link formed by links 2 and $5^{\prime}$ is used to fractionate the mechanism shown in Figure 5 into its constitutive gear train entities (GTEs): the planetary gear train entity (PGTE) containing links $1,2,3,3^{\prime}$, and 4 and the ordinary gear train entity (OGTE) containing links 5 and $5^{\prime}$.

Before continuing with the other steps, we will introduce here a definition to the active link. An active link is any link that transmits power to neighboring links (common links) or to the surrounding environment (input, output, and fixed links), when an entity (GPE, GTE, or PGT) is viewed in isolation from neighboring entities. Links 1, 2, and 4 are the active links of the subsystem containing GPE1 and GPE2, while links 1, $2^{\prime}$, and 3 are the active links of GPE1. Note that link 2 and link $2^{\prime}$ are different labels for the same common link for differentiation.

Step 3. For the ordinary gear train entity which consists of gears 5 and $5^{\prime}$, we shall assume that gear 5 is rotating in the negative counterclockwise direction. This implies that gear $5^{\prime}$ is rotating in the opposite direction and the planet carrier 2 which is rigidly connected to gear $5^{\prime}$ must rotate with it at the same speed and in the same direction, that is to say

$$
-\omega_{5}=\omega_{2}=\omega_{5^{\prime}}
$$

It is well known that the input power is positive $\left(P_{\text {in }}>0\right)$ and the output power is negative $\left(P_{\text {out }}<0\right)$. Since link 5 is an input link in the gearing system $\left(P_{5}>0\right)$, its angular velocity was assumed to be negative $\left(\omega_{5}<0\right)$, so its torque must be negative $\left(T_{5}<0\right)$ so that the negative torque multiplied by the negative angular velocity becomes a positive input power. Similarly, since link $5^{\prime}$ is the output link in the OGTE $\left(P_{5^{\prime}}\right.$ $<0)$, its angular velocity is positive $\left(\omega_{5^{\prime}}>0\right)$, so its torque must be negative $\left(T_{5^{\prime}}<0\right)$ too. The power flow through the OGTE is shown in Figure 6.

Step 4. The output power from link $5^{\prime}$ which belongs to the OGTE is the input power to the PGTE through link 2. That is to say $P_{2}=-P_{5^{\prime}}$, but $P_{2}=T_{2} \cdot \omega_{2}=-T_{5^{\prime}} \cdot \omega_{5^{\prime}}$ and $\omega_{2}=\omega_{5^{\prime}}$; therefore, $T_{2}=-T_{5^{\prime}}$. Since $T_{5^{\prime}}<0$, then $T_{2}>0$.

So far, we have come to the following result: the torque and speed of link 2 are both positive; $\left(\omega_{2}>0\right)$ and $\left(T_{2}>0\right)$.

Step 5. Operating conditions for the PGTE.

We have previously assumed for the clarity of the solution that $R_{1,3}^{2^{\prime}}=-28 / 36, R_{4,3^{\prime}}^{2^{\prime \prime}}=-36 / 28$. Since $R_{4,3^{\prime}}^{2^{\prime \prime}}<R_{1,3}^{2}<0$, then from Equation (23), the velocity sequence is $\omega_{4}: \omega_{1}$ $: \omega_{2}: \omega_{3}$. For links 1,2 , and 4 , the velocity sequence is $\omega_{4}$ : $\omega_{1}: \omega_{2}$. By substituting $x=4, y=1$, and $z=2$ in the torque ratios of Equations (10) and (12), we get $T_{2} / T_{4}>0$ and $T_{1} /$ $\mathrm{T}_{4}<0$

Since $T_{2}$ is positive, then $T_{4}$ is positive too and $T_{1}$ must be negative. Since $T_{4}>0$, then $\omega_{4}$ must be positive for link 4 to be an input link in the gearing system. Similarly, since $T_{1}<0$, then $\omega_{1}$ must be positive for link 1 to be an output link in the gearing system. In fact, $\omega_{1}$ is really positive because it is intermediate between two positive values $\omega_{2}$ and $\omega_{4}$.

Step 6. Because of the possibility of power flow through several paths in the gearing system, there is a probability that part of the power will continue to circulate within the 


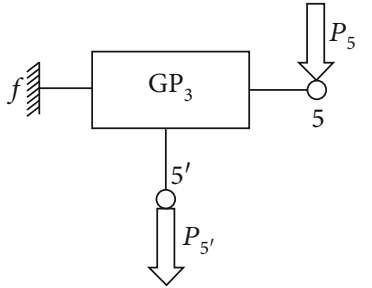

Figure 6: Power flow through the OGTE.

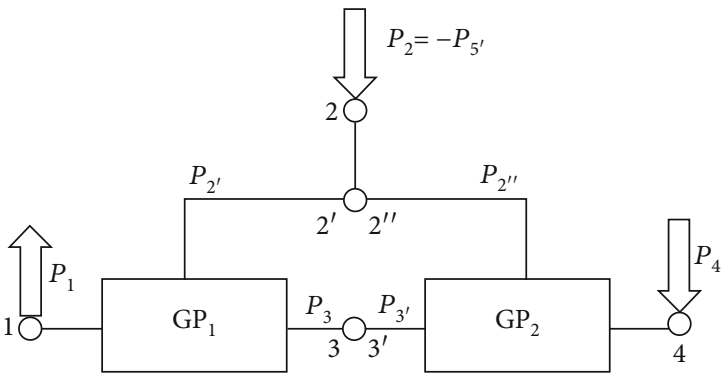

FIgURe 7: Input and output powers to the PGTE.

elements of the system without going to the output link. Therefore, we have to study the flow of power through the elements of the system in the ascending and descending velocity sequence.

Case 1. Ascending velocity sequence $\omega_{4}<\omega_{1}<\omega_{2}<\omega_{3}$. Since $\omega_{4}>0$, then $0<\omega_{4}<\omega_{1}<\omega_{2}<\omega_{3}$.

Case 2. Descending velocity sequence $\omega_{4}>\omega_{1}>\omega_{2}>\omega_{3}$. Since $\omega_{2}>0$, then there are two subcases:

(a) $\omega_{4}>\omega_{1}>\omega_{2}>0>\omega_{3}$

(b) $\omega_{4}>\omega_{1}>\omega_{2}>\omega_{3}>0$

Note that all the velocities in Case 1 and Case 2(b) above are positive or greater than zero. In Case $2(\mathrm{a})$, only $\omega_{3}$ is negative.

Step 7. The common links 2 and 3 are used to fractionate the PGTE shown in Figure 7 into its constitutive GPEs: GPE1 containing links $1,2^{\prime}$, and 3 and GPE2 containing links 4 , $2^{\prime \prime}$, and $3^{\prime}$.

Step 8. For GPE1 containing links $1,2^{\prime}$, and 3 , the velocity sequence is $\omega_{1}: \omega_{2}: \omega_{3}$. By substituting $x=1, y=2^{\prime}$, and $z$ $=3$ in the torque ratios of Equations (10) and (12), we get $T_{3} / T_{1}>0$ and $T_{2^{2}} / T_{1}<0$.

Since $T_{1}<0$, then $T_{3}<0$ and $T_{2^{\prime}}>0$. Also because all the velocities in Case 1 and Case 2(b) are positive, then $\left(P_{1}=\right.$ $\left.T_{1} \cdot \omega_{1}\right)<0,\left(P_{3}=T_{3} \cdot \omega_{3}\right)<0$, and $\left(P_{2^{\prime}}=T_{2^{\prime}} \cdot \omega_{2^{\prime}}\right)>0$. Link 2 $'$ is the input link in GPE1, while links 1 and 3 are output links (see Figure 8).

For Case 2(a), $\omega_{1}$ and $\omega_{2^{\prime}}$ are positive while $\omega_{3}$ is negative; therefore, $\left(P_{1}=T_{1} \cdot \omega_{1}\right)<0,\left(P_{3}=T_{3} \cdot \omega_{3}\right)>0$, and $\left(P_{2^{\prime}}=T_{2^{\prime}}\right.$.

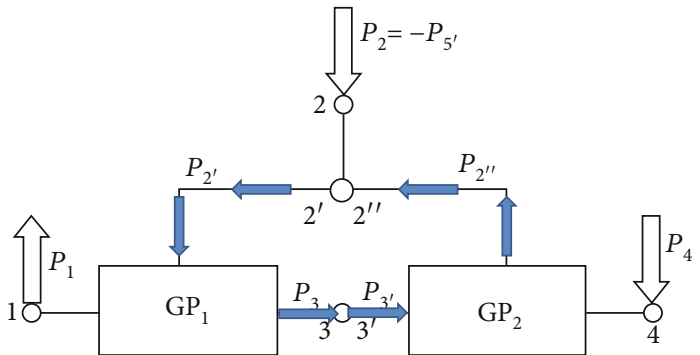

Figure 8: Power flow when $\omega_{4}, \omega_{1}, \omega_{2}$, and $\omega_{3}>0$.

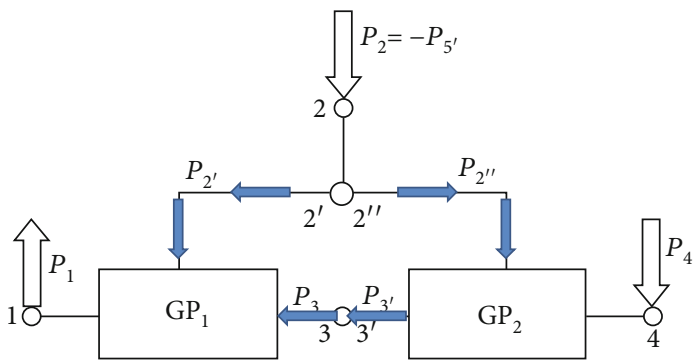

FIgURe 9: Power flow when $\omega_{4}>\omega_{1}>\omega_{2}>0>\omega_{3}$.

$\left.\omega_{2^{\prime}}\right)>0$. Link 1 is the output link in GPE1, while links $2^{\prime}$ and 3 are input links (see Figure 9).

Step 9. For GPE2 containing links $4,2^{\prime \prime}$, and $3^{\prime}$, the velocity sequence is $\omega_{4}: \omega_{2}: \omega_{3}$. By substituting $x=4, y=2^{\prime \prime}$, and $z=3^{\prime}$ in the torque ratios of Equations (10) and (12), we get $T_{3^{\prime}} / T_{4}>0$ and $T_{2^{\prime \prime}} / T_{4}<0$.

Since $T_{4}>0$, then $T_{3^{\prime}}>0$ and $T_{2^{\prime \prime}}<0$. Also because all the velocities in Case 1 and Case 2(b) are positive, then $\left(P_{4}\right.$ $\left.=T_{4} \cdot \omega_{4}\right)>0,\left(P_{3^{\prime}}=T_{3^{\prime}} \cdot \omega_{3^{\prime}}\right)>0$, and $\left(P_{2^{\prime \prime}}=T_{2^{\prime \prime}} \cdot \omega_{2^{\prime \prime}}\right)<0$. Link $2^{\prime \prime}$ is the output link in GPE2, while links 4 and $3^{\prime}$ are input links (see Figure 8).

For Case 2(a), $\omega_{4}$ and $\omega_{2^{\prime \prime}}$ are positive while $\omega_{3^{\prime}}$ is negative; therefore, $\left(P_{4}=T_{4} \cdot \omega_{4}\right)>0, \quad\left(P_{3^{\prime}}=T_{3^{\prime}} \cdot \omega_{3^{\prime}}\right)<0$, and $\left(P_{2^{\prime \prime}}=T_{2^{\prime \prime}} \cdot \omega_{2^{\prime \prime}}\right)>0$. Link $3^{\prime}$ is the output link in GPE2, while links 4 and $2^{\prime \prime}$ are input links (see Figure 9).

The results above can be summarized as in Table 1 .

Step 10. Condition for power circulation.

From Equation (3), we can write the expression for the velocity ratio $R_{2,4}^{3^{\prime}}$ as

$$
R_{2,4}^{3^{\prime}}=\frac{1}{1-R_{4, p}^{c}}=\frac{\omega_{2}-\omega_{3^{\prime}}}{\omega_{4}-\omega_{3^{\prime}}} .
$$

When $\omega_{3^{\prime}}=0$,

$$
\frac{\omega_{2}}{\omega_{4}}=\frac{1}{1-R_{4,3^{\prime}}^{c}} .
$$

But $R_{4,3^{\prime}}^{c}=-Z_{3^{\prime}} / Z_{4}$, then by substituting the value of $R_{4,3^{\prime}}^{c}$ 
TABLE 1: Gear pair entity, gear train entity (GTE), and torque for the mechanism shown in Figure 1 which has a velocity sequence of $\omega_{4}$ $: \omega_{1}: \omega_{2}: \omega_{3}$

\begin{tabular}{|c|c|c|c|c|c|c|c|c|}
\hline \multirow{3}{*}{$\begin{array}{l}\text { Active links of GPEs } \\
\text { or their combination }\end{array}$} & \multicolumn{5}{|c|}{ Velocity sequence $\omega_{x}: \omega_{y}: \omega_{z}$} & \multirow{3}{*}{ Known torque } & \multirow{3}{*}{$\begin{array}{l}\text { Torque concluded } \\
\text { from column } 5\end{array}$} & \multirow{3}{*}{$\begin{array}{l}\text { Torque concluded } \\
\text { from column } 6\end{array}$} \\
\hline & \multicolumn{3}{|c|}{ Assignment } & \multicolumn{2}{|c|}{$\begin{aligned} \text { nce } \omega_{x}: \omega_{y}: \omega_{z} \\
\text { Torque ratio }\end{aligned}$} & & & \\
\hline & $x$ & $y$ & $z$ & $\frac{T_{z}}{T_{x}}>0$ & $\frac{T_{y}}{T_{x}}<0$ & & & \\
\hline$(\mathrm{GPE} 1+\mathrm{GPE} 2)$ 1, 2, 4 & 4 & 1 & 2 & $\frac{T_{2}}{T_{4}}>0$ & $\frac{T_{1}}{T_{4}}<0$ & $\begin{array}{c}T_{2}>0 \\
\text { From previous section }\end{array}$ & $T_{4}>0$ & $T_{1}<0$ \\
\hline $\begin{array}{l}\text { GPE1 } \\
1,2^{\prime}, 3\end{array}$ & 1 & $2^{\prime}$ & 3 & $\frac{T_{3}}{T_{1}}>0$ & $\frac{T_{2^{\prime}}}{T_{1}}<0$ & $\begin{array}{l}T_{1}<0 \\
\text { Entry } \\
(2,9)\end{array}$ & $T_{3}<0$ & $T_{2^{\prime}}>0$ \\
\hline $\begin{array}{l}\text { GPE2 } \\
2^{\prime \prime}, 3^{\prime}, 4\end{array}$ & 4 & $2^{\prime \prime}$ & $3^{\prime}$ & $\frac{T_{3^{\prime}}}{T_{4}}>0$ & $\frac{T_{2^{\prime \prime}}}{T_{4}}<0$ & $\begin{array}{c}T_{4}>0 \text { entry } \\
(2,8)\end{array}$ & $T_{3^{\prime}}>0$ & $T_{2^{\prime \prime}}<0$ \\
\hline
\end{tabular}

into Equation (26) and simplifying, we get

$$
\frac{\omega_{2}}{\omega_{4}}=\frac{Z_{4}}{Z_{3^{\prime}}+Z_{4}} .
$$

If the ratio of the two input velocities $\left(\omega_{2} / \omega_{4}\right)$ is $\left(Z_{4} /\right.$ $\left.\left(Z_{3^{\prime}}+Z_{4}\right)\right)$, then $\omega_{3^{\prime}}=0$.

If $\left(\omega_{2} / \omega_{4}\right)<\left(Z_{4} /\left(Z_{3^{\prime}}+Z_{4}\right)\right)$, then $\omega_{3^{\prime}}<0$ and there is no power circulation.

If $\left(\omega_{2} / \omega_{4}\right)>\left(Z_{4} /\left(Z_{3^{\prime}}+Z_{4}\right)\right)$, then $\omega_{3^{\prime}}>0$ and power circulation becomes inevitable.

\section{Effect of Power Circulation on Power Losses}

Although the power flow in the system is studied by other researchers $[10,34,35]$, no one has indicated the existence of power circulation or the conditions under which it occurs or the loop in which it circulates. In the current study, the conditions under which power is circulated are determined and a GTE diagram is drawn to show how the power is circulated through the mechanism (Figure 8). Back to Figure 8, it is possible to follow the loop at which power circulation occurs. For GP1, $P_{2^{\prime}}$ is input and $P_{1}$ and $P_{3}$ are outputs, while for GP2, $P_{4}$ and $P_{3^{\prime}}$ are inputs and $P_{2^{\prime \prime}}$ is output. The power $P_{2^{\prime}}$ is due to the confluence of the powers $P_{2}$ and $P_{2^{\prime \prime}} . P_{2}$ and $P_{2^{\prime \prime}}$ are the two input powers to the planet carrier 2, while $P_{2^{\prime}}$ is the output power from it. Part of $P_{2}$, will go to the output (link 1), while the other part will flow through planet 3 . The output power from planet gear 3 is the input power to the planet gear $3^{\prime} . P_{3^{\prime}}$ is part of $P_{2^{\prime \prime}}$ while $P_{3}$ is part of $P_{2^{\prime}}$. Figure 10 shows the same power flow but on the schematic drawing of the actual mechanism.

As shown in Figure 10, $P_{3}$ flows through planet gear 3 to planet gear $3^{\prime}$. Then, it goes to carrier 2 from which it goes to planet gear 3 . The red arrows show the power that circulates through the PGT. The occurrence of power circulation between the planet gears and the planet gear carrier is rare and can only be sensed with extreme difficulty.

Since "gear mesh losses have dominant impacts on the overall performance of the gear system" [41], only power losses resulting from sliding friction of gears are considered.

It should be noted that

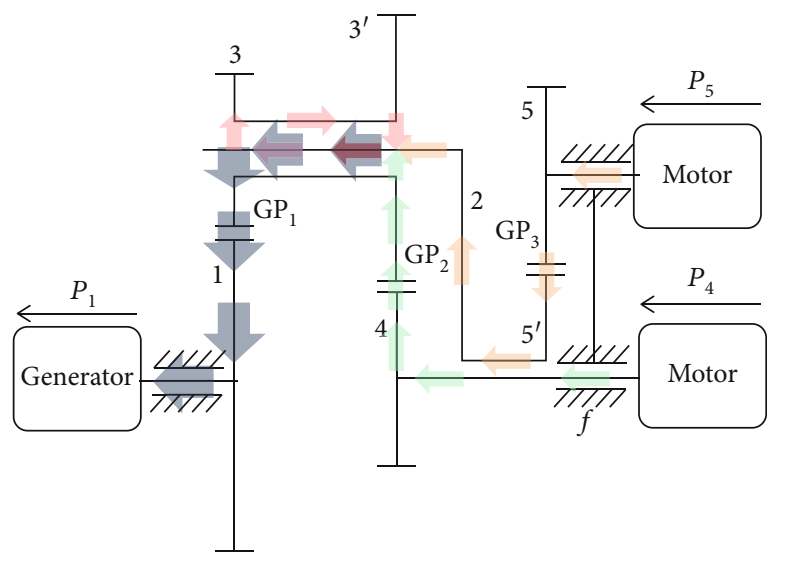

FIgURE 10: Power flow through different elements of the mechanism.

(1) The power that circulates through the planetary gear train does not cross any of the three gear pairs $\mathrm{GP}_{1}$, $\mathrm{GP}_{2}$, or $\mathrm{GP}_{3}$ where power losses are considered

(2) Although the circulating power amplifies the power passing through the carrier, it does not affect the total power losses because the power losses in bearings supporting the planet gears are negligible compared to the power losses resulting from sliding friction of gears [41]

\section{Power Flow, Power Losses, and Efficiency}

The procedure for estimating the power losses and the overall efficiency of the mechanism shown in Figure 1 is as follows:

9.1. For the OGTE. Since the carrier is the fixed link in any OGTE, then the input (output) link in the FRF is the same as that in the MRF. In this case, links 5 and $5^{\prime}$ are the input and output links, respectively, while the casing (link $f$ ) is considered as the stationary link. By assigning $x=5, y=5^{\prime}$, and $z=c=f$ and excluding the mathematical expression containing $P_{z}$ from Equation (14), the following equation is obtained: 


$$
\frac{P_{5}}{R_{5^{\prime}, 5}^{f}}=-\frac{P_{5^{\prime}}}{\eta_{f\left(5-5^{\prime}\right) R_{5^{\prime}, 5}^{f}}}=\frac{P_{5}^{f}}{R_{5^{\prime}, 5}^{f}\left(1-R_{f, 5}^{f}\right)} .
$$

After simplifying Equation (28), we get

$$
P_{5}=-\frac{P_{5^{\prime}}}{\eta_{f\left(5-5^{\prime}\right)}}=P_{5}^{f} .
$$

From Equation (29), it is clear that the potential power $\left(P_{5}^{f}\right)$ of the OGTE is the same as the actual power $\left(P_{5}\right)$. In addition from Equation (29), the efficiency of the OGTE is

$$
\eta_{f\left(5-5^{\prime}\right)}=\eta_{3}=-\frac{P_{5^{\prime}}}{P_{5}}
$$

or

$$
-P_{5^{\prime}}=\eta_{3} P_{5}
$$

The power balance of link $5^{\prime}$ is given by

$$
P_{2}+P_{5^{\prime}}=0 .
$$

Substituting Equation (31) into Equation (32), we get

$$
P_{2}=\eta_{3} P_{5} .
$$

Therefore, the friction loss of the OGTE is given by

$$
l_{3}=\left(\eta_{3}-1\right) P_{5} .
$$

Substituting Equation (33) into Equation (34), we get

$$
l_{3}=\frac{\left(\eta_{3}-1\right)}{\eta_{3}} P_{2} .
$$

9.2. For the PGTE. As before, we have to study the power losses and the efficiency of the PGTE in the ascending and descending velocity sequences. In the beginning, we need to retrieve the results that we obtained previously for the active links of the PGTE (links 1, 2, and 4) for $R_{4,3^{\prime}}^{2^{\prime \prime}}<R_{1,3}^{2}<0$. From Table 1, we have

(1) $T_{4}>0, T_{1}<0$, and $T_{2}>0$

(2) $\omega_{4}: \omega_{1}: \omega_{2}$

In a MRF in which link 2 seems relatively stationary, the relative velocities will appear to an observer standing on the carrier as $\left(\omega_{4}-\omega_{2}\right):\left(\omega_{1}-\omega_{2}\right): 0$.

Case 1. Ascending velocity sequence

$$
\left(\omega_{4}-\omega_{2}\right)<\left(\omega_{1}-\omega_{2}\right)<0 .
$$

Since $\left(\omega_{1}-\omega_{2}\right)<0$ and $T_{1}<0$, then $T_{1}\left(\omega_{1}-\omega_{2}\right)>0$, so link 1 is a driving link in the MRF.
TABle 2: Velocity ratios of the example PGT.

Velocity ratios

$R_{4,1}^{2}=\frac{1}{R_{1,4}^{2}}=\frac{81}{49}$

$R_{1,4}^{f}=\frac{1}{R_{4,1}^{f}}=\frac{32 k+49}{81}$

$R_{2,1}^{f}=\frac{81 k}{32 k+49}$

$R_{2, f}^{1}=\frac{49 k-49}{-32 k-49}$

By assigning $x=1, y=4$, and $z=2$ into Equation (14), we get

$$
\frac{P_{1}}{R_{4,1}^{2}}=-\frac{P_{4}}{\eta_{2(1-4) R_{4,1}^{f}}}=\frac{P_{2}}{\left(\eta_{2(1-4)}-R_{4,1}^{2}\right) R_{2,1}^{f}}=\frac{P_{1}^{2}}{R_{4,1}^{2} R_{2, f}^{1}} .
$$

From Equation (7), the losses can be written separately for each gear pair, as the following:

$$
l_{1}=\left(\eta_{1}-1\right) P_{1}^{2} .
$$

However, from Equation (37), we have

$$
P_{1}^{2}=R_{2, f}^{1} P_{1} .
$$

Then, Equation (38) becomes

$$
l_{1}=\left(\eta_{1}-1\right) R_{2, f}^{1} P_{1},
$$

similarly

$$
l_{2}=\eta_{1}\left(\eta_{2}-1\right) R_{2, f}^{1} P_{1} .
$$

From Equation (37),

$$
P_{2}=\left(\frac{\eta_{2(1-4)}}{R_{4,1}^{2}}-1\right) R_{2,1}^{f} P_{1} .
$$

Substituting Equation (42) into Equation (35), the friction loss of the OGTE can be written in terms of $P_{1}$ as

$$
l_{3}=\frac{\left(\eta_{3}-1\right)}{\eta_{3}}\left(\frac{\eta_{2(1 \rightarrow 4)}}{R_{4,1}^{2}}-1\right) R_{2,1}^{f} P_{1}
$$

The overall tooth friction loss $l\left(=l_{1}+l_{2}+l_{3}\right)$ is given after simplification as follows:

$$
l=\left\{\left(\eta_{1} \eta_{2}-1\right)-\left(\eta_{1} \eta_{2}-1\right) R_{2,1}^{f}+\frac{\left(\eta_{3}-1\right)}{\eta_{3}}\left[\frac{\eta_{1} \eta_{2}}{R_{4,1}^{2}}-1\right] R_{2,1}^{f}\right\} P_{1} .
$$

To estimate the total efficiency of the gear train, 
substitute Equation (44) into $\eta_{p}=1 /\left(1+\left(l / P_{\text {out }}\right)\right)$, to obtain $\eta_{(5,4 \rightarrow 1)}=\frac{1}{\eta_{1} \eta_{2}+\left\{\left(\left(\eta_{3}-1\right) / \eta_{3}\right)\left[\left(\eta_{1} \eta_{2} / R_{4,1}^{2}\right)-1\right]-\left(\eta_{1} \eta_{2}-1\right)\right\} R_{2,1}^{f}}$.

The power loss $l$ can be written also in the following form:

$$
l=\left[\eta_{(5,4 \rightarrow 1)}-1\right] P_{\text {in }} .
$$

Substituting Equation (45) into Equation (46) and assuming that $P_{\text {in }}=1$, we get

$$
l=\frac{1}{\eta_{1} \eta_{2}+\left\{\left(\left(\eta_{3}-1\right) / \eta_{3}\right)\left[\left(\eta_{1} \eta_{2} / R_{4,1}^{2}\right)-1\right]-\left(\eta_{1} \eta_{2}-1\right)\right\} R_{2,1}^{f}}-1 .
$$

Using the results derived in Velocity Ratio Analysis, the velocity ratios that appear in the previous equations are calculated from Equations (1) through (4) as shown in Table 2. Note that $k$ represents the input velocity ratio $\left(R_{2,4}^{f}=\omega_{2} / \omega_{4}\right)$.

Let us further assume that the efficiencies of the three gear pairs $\left(\eta_{1}, \eta_{2}, \eta_{3}\right)$ are known. By making use of the velocity ratios tabulated in Table 2, we can obtain from Equations (47), (45), (44), (43), (41), (40), (37), and (33), by back substituting the values of the following variables: $l, \eta_{(5,4 \rightarrow 1)}$, $P_{1}, l_{3}, l_{2}, l_{1}, P_{2}, P_{4}$, and $P_{5}$, respectively.

Case 2. Descending velocity sequence: $\left(\omega_{4}-\omega_{2}\right)>\left(\omega_{1}-\omega_{2}\right)$ $>0$.
By assigning $x=4, y=1$, and $z=2$ in Equation (14), we get

$$
\frac{P_{4}}{R_{1,4}^{2}}=-\frac{P_{1}}{\eta_{2(4-1)} R_{1,4}^{f}}=\frac{P_{2}}{\left(\eta_{2(4-1)}-R_{1,4}^{2}\right) R_{2,4}^{f}}=\frac{P_{4}^{2}}{R_{1,4}^{2} R_{2, f}^{4}} .
$$

As before, the friction losses can be written separately for each gear pair in terms of $P_{1}$, as follows:

$$
\begin{gathered}
l_{2}=\left(1-\eta_{2}\right)\left(\frac{R_{2, f}^{1}}{\eta_{1} \eta_{2}}\right) P_{1}, \\
l_{1}=\left(\eta_{2}-\eta_{1} \eta_{2}\right)\left(\frac{R_{2, f}^{1}}{\eta_{1} \eta_{2}}\right) P_{1}, \\
l_{3}=\frac{\left(1-\eta_{3}\right)}{\eta_{1} \eta_{2} \eta_{3}}\left(\eta_{1} \eta_{2}-R_{1,4}^{2}\right) R_{2,1}^{f} P_{1} .
\end{gathered}
$$

The overall tooth friction loss $(l)$ is

$l=\left[\left(1-\eta_{2}\right)\left(\frac{R_{2, f}^{1}}{\eta_{1} \eta_{2}}\right)+\left(\eta_{2}-\eta_{1} \eta_{2}\right)\left(\frac{R_{2, f}^{1}}{\eta_{1} \eta_{2}}\right)+\frac{\left(1-\eta_{3}\right)}{\eta_{1} \eta_{2} \eta_{3}}\left(\eta_{1} \eta_{2}-R_{1,4}^{2}\right) R_{2,1}^{f}\right] P_{1}$.

To estimate the total efficiency of the gear train, we substitute Equation (52) into efficiency formula, $\eta_{p}=1 / 1$ $+\left(l / P_{\text {out }}\right)$, where $P_{\text {out }}=P_{1}$ and get

$$
\eta_{(5,4 \rightarrow 1)}=\frac{1}{1+\left[\left(1-\eta_{2}\right)\left(R_{2, f}^{1} / \eta_{1} \eta_{2}\right)+\left(\eta_{2}-\eta_{1} \eta_{2}\right)\left(R_{2, f}^{1} / \eta_{1} \eta_{2}\right)+\left(\left(1-\eta_{3}\right) / \eta_{1} \eta_{2} \eta_{3}\right)\left(\eta_{1} \eta_{2}-R_{1,4}^{2}\right) R_{2,1}^{f}\right]} .
$$

As before, $l$ is simplified to

$$
l=\frac{1}{1+\left[\left(1-\eta_{2}\right)\left(R_{2, f}^{1} / \eta_{1} \eta_{2}\right)+\left(\eta_{2}-\eta_{1} \eta_{2}\right)\left(R_{2, f}^{1} / \eta_{1} \eta_{2}\right)+\left(\left(1-\eta_{3}\right) / \eta_{1} \eta_{2} \eta_{3}\right)\left(\eta_{1} \eta_{2}-R_{1,4}^{2}\right) R_{2,1}^{f}\right]}-1 .
$$

For an input power $P_{\text {in }}=1$, the values of the following variables: $l, \eta_{(5,4 \rightarrow 1)}, P_{1}, l_{2}, l_{1}, l_{3}, P_{2}, P_{4}$, and $P_{5}$, we can obtain, respectively, from Equations (54), (53), (52), (49), (50), (51), (48), and (33) by back substitution.

\section{Numerical Results and Discussion}

To validate the theoretical results experimentally, the current results are compared with experimental data of a previous work [35]. To make the theoretical results closer to reality, the local efficiencies of the three gear pairs $\left(\eta_{1}, \eta_{2}, \eta_{3}\right)$ are also extracted from those experimental data. With $k\left(=\omega_{2} / \omega_{4}=1\right.$ $\left.\omega_{5} / \omega_{4} \mid\right)$ as a variable, the efficiency is drawn in Figure 10, for a complete range of input velocity ratios $\left|\omega_{5} / \omega_{4}\right|$. Only the experimental data used in plotting Figure 10 are listed in Table 3. For complete information about the experimental device and experimental data, one can refer to Reference [35]. Although the predicted power losses are continuous across the two ranges of $k(k<1$ and $k>1)$, there is a leap when $k=1$. However, as expected, the predicted losses fall 
Table 3: Experimental data for the two input PGT shown in Figure 3 when the torque on link 1 is 1.5 [49]*.

\begin{tabular}{|c|c|c|c|c|c|c|c|}
\hline$k=\omega_{2} / \omega_{4}$ & $\omega(4)^{*} *$ & Torque $(4)^{* * *}$ & $\omega(5)(=-\omega(2))^{*}$ & Torque(5) & $\omega(1)^{* * * *}$ & Torque(1) & Efficiency ${ }^{* * * * *}$ \\
\hline 0 & -100 & -0.8670 & 0 & 0.3397 & -48 & 1.5 & 0.830450 \\
\hline 0.2679 & -149.282 & -0.8821 & 40 & 0.7337 & -92 & 1.5 & 0.856985 \\
\hline 0.3640 & -100 & -0.8593 & 36.39702 & 0.7488 & -65 & 1.5 & 0.861428 \\
\hline 0.4663 & -100 & -0.8697 & 46.63077 & 0.7688 & -71 & 1.5 & 0.867125 \\
\hline 0.5774 & -100 & -0.8618 & 57.73503 & 0.776 & -76 & 1.5 & 0.870346 \\
\hline 0.7002 & -100 & -0.8621 & 70.02075 & 0.783 & -82 & 1.5 & 0.872116 \\
\hline 0.8391 & -100 & -0.8608 & 83.90996 & 0.773 & -88 & 1.5 & 0.874506 \\
\hline 1.0000 & -100 & -0.8486 & 100 & 0.7512 & -93 & 1.5 & 0.871948 \\
\hline 1 & & & & & & & 0.820883 \\
\hline 1.1918 & -100 & -0.7639 & 119.1754 & 0.9068 & -100 & 1.5 & 0.813192 \\
\hline 1.4281 & -100 & -0.7514 & 142.8148 & 0.9295 & -111 & 1.5 & 0.800918 \\
\hline 1.7321 & -100 & -0.7493 & 173.2051 & 0.9522 & -119 & 1.5 & 0.744197 \\
\hline 2.1445 & -40 & -0.7687 & 85.78028 & 0.8218 & -50 & 1.5 & 0.740798 \\
\hline 2.7475 & -40 & -0.7573 & 109.8991 & 0.8185 & -57 & 1.5 & 0.711052 \\
\hline 3.7321 & -40 & -0.7504 & 149.282 & 0.8031 & -66 & 1.5 & 0.660421 \\
\hline
\end{tabular}

${ }^{*}$ Each point was measured only when the system reaches constant speeds. ${ }^{* *} \mathrm{CCW}+.{ }^{* * *}$ The torque sensors can measure up to $2.5 \mathrm{~N} \cdot \mathrm{m}$ of torque with a precision of $0.1 \%$ of this range. ${ }^{* * * *}$ The optical speed sensors are capable of measuring up to $3000 \mathrm{rpm}$ and are accurate to within $1 \mathrm{rpm} .{ }^{* * * * *}$ Note that there is no surface treatment or lubricant applied on the teeth surfaces.

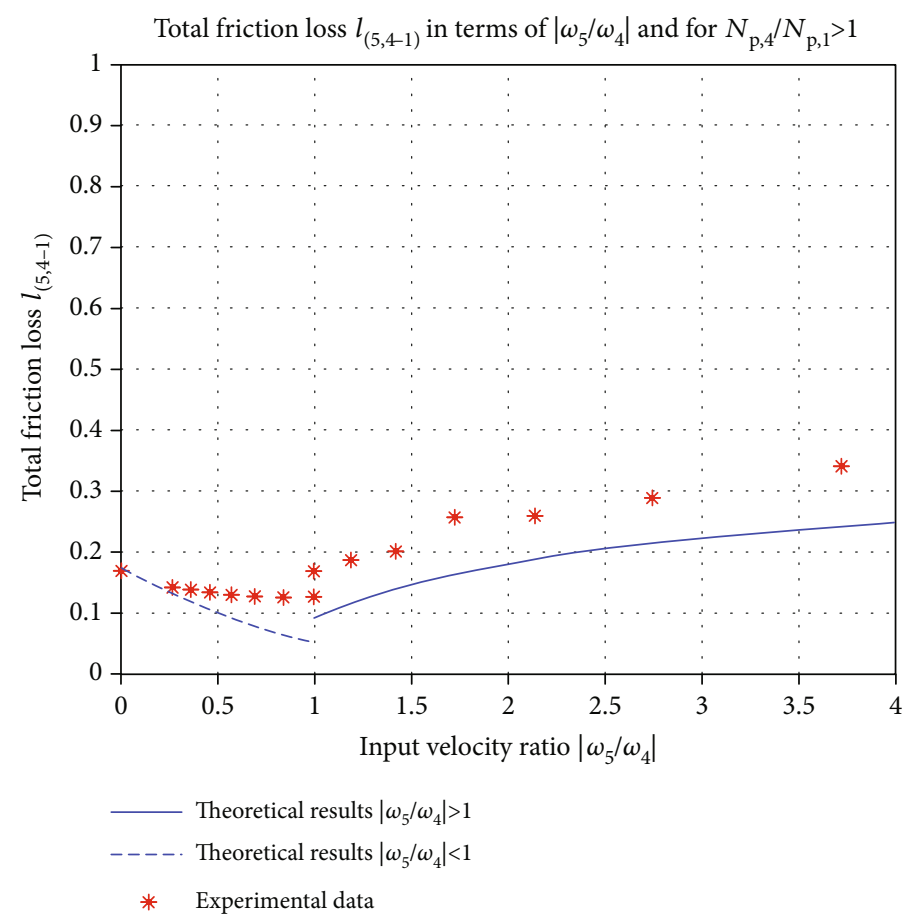

FIGURE 11: Comparison between the experimental data and theoretical results.

within the physically possible range of $0<l<1$. We also observe that for $k>1$, power losses are steadily increasing while decreasing at a decreasing rate when $k<1$.

To verify these results theoretically and experimentally, other conditions are explored as follows:

(1) $k=0$. In this case, since the carrier shaft is fixed, GP3 is stationary and the system involves only GP1 and GP2. From this condition, the coupled efficiency $\eta_{12}$ $=\eta_{1} \eta_{2}$ can be found experimentally. From the experimental data given in Reference [35] for an identical system, and wherever $\omega_{2}=0$, the coupled efficiency, $\eta_{1} \eta_{2}$, can be read as $0.8218,0.8240,0.8280$, and 0.8305 at four different experimental cases. The mean value of the coupled efficiency $\eta_{12}$ is 0.8261 . The experimental mean value of the coupled efficiency has been used in the friction loss expressions to find the theoretical friction loss curves of Figure 11 
(2) There is a distinctive jump in the friction losses when the range of the input velocity ratio changes from $k<$ 1 to $k>1$, which reveals that different power loss mechanisms would prompt different tooth friction losses. The left and right curves of Figure 11 illustrate the effect of the change in power flow pattern (within Cases 1 and 2 above) on the friction losses. This phenomenon is an example of an interesting peculiarity in the analysis

(3) $k=1$. At this case, all elements of the planetary part of the train are rotating at the same angular velocity. This means that there is no relative motion between its mating gears. This results in no friction losses in this part of the train, i.e., $\eta_{1} \eta_{2}=1$. The only losses are that of the ordinary part of the train or that of GP3. Under this condition, the efficiency $\eta_{3}$ for GP3 can be found directly from the experimental data given in [35]. Wherever $\omega_{2}=\omega_{4}=\omega_{1}$ is met in the tabulated experimental data, $\eta_{3}$ can be read. At two different cases, it was 0.8209 and 0.8435 . A mean value of 0.8322 is substituted into the friction loss expressions of the present analysis to find the theoretical friction loss curves of Figure 11. In Figure 11, the deviation between the theoretical and experimental data may be due to other losses that have not been taken into account in the present analysis

(4) The experimental value of $\eta_{3}(=0.8322)$ calculated by the present method is much higher than the mean value calculated by Chen and Chen [35], ranging between 0.6442 and 0.7265 . Unfortunately, they calculated $\eta_{3}$ theoretically from their simplified expression of efficiency and did not take it directly from experimental data. That is why $\eta_{3}$ has dropped to this unreasonable value which does not match even with their own experimental data

(5) $k \rightarrow 1$.Under this condition, the losses of the planetary part of the train are approaching zero $\left(l_{1}+l_{2} \rightarrow 0\right)$ as $k$ approaches 1 from both the left and right sides of Figure 12. This means that $l$ decreases as $k$ approaches 1 . This can also be seen in Figure 11, which confirms that theoretical predictions are consistent with experimental observations. From Figure 12, it is noticed that the leap in the power losses returns only to the losses in the ordinary gear train entity (GP3). In fact, the jump is due to the change in the power flow pattern in the PGTE (as will be shown in Figure 13).

Note that the power losses $l_{1}$ and $l_{2}$ decrease with the increase of $k$, while $l_{3}$ increases until $k$ reaches 1 . For $k>1$, the three losses increase steadily. For large values of $k$ (not shown in the figure), the theoretical losses approach asymptotically to a value of 0.35

(6) To illustrate the effect of the power flow pattern on the losses jump, let us recall that $P_{2}=\eta_{3} P_{5}$. Since $P_{2}$

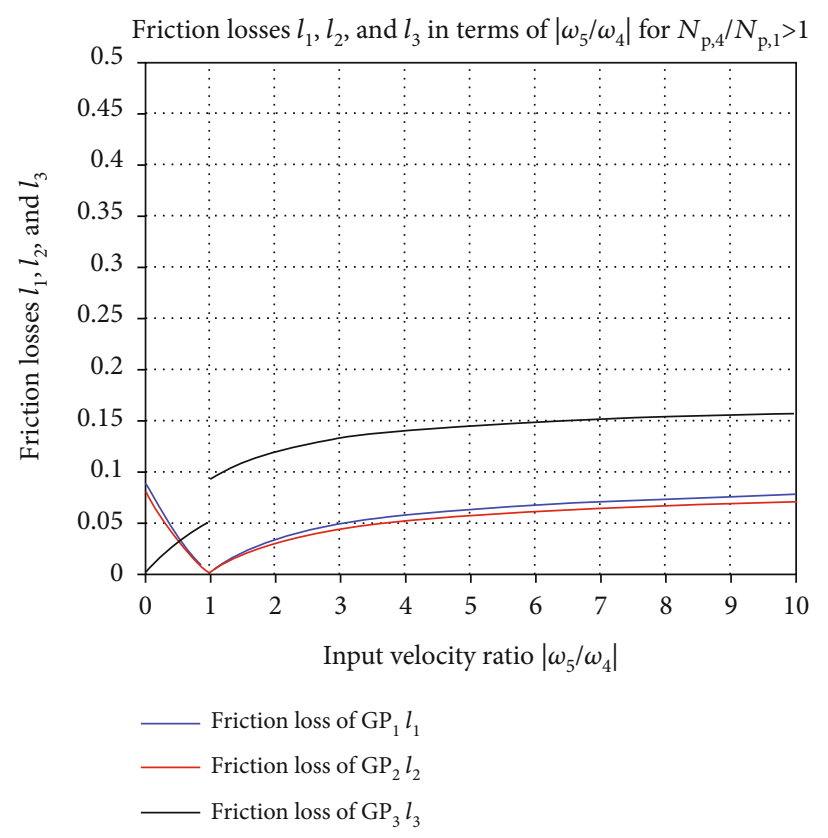

FIGURE 12: Friction losses with input velocity ratio.

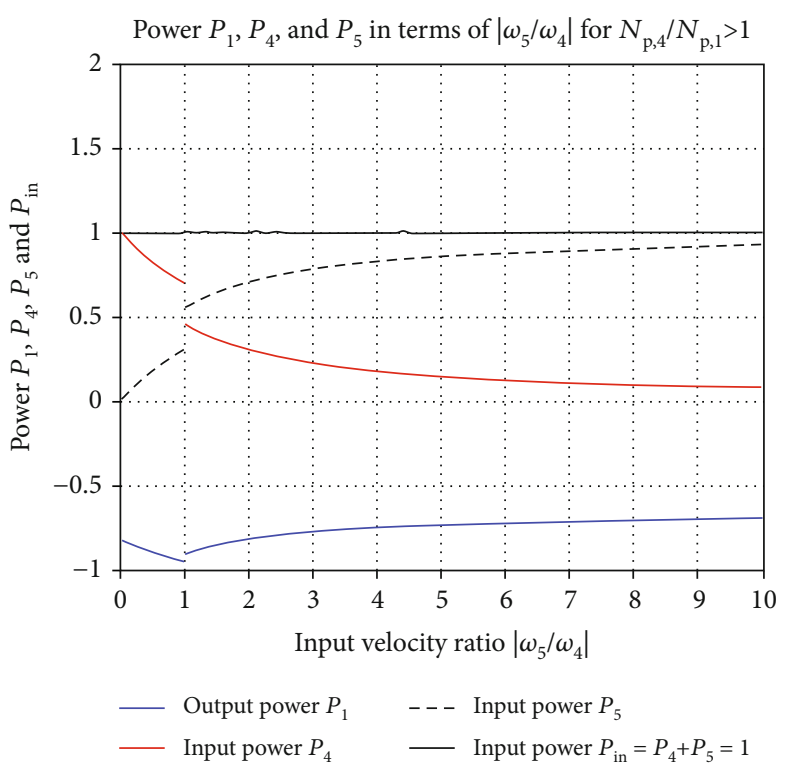

Figure 13: Input and output powers with input velocity ratio.

is somewhat less than and has the same trend as $P_{5}$, we will draw $P_{5}$ only. As shown in Figure 13, $P_{4}$ decreases as $k$ increases with a sudden fall at $k=1$, while $P_{2}$ increases as $k$ increases with a sudden rise at $k=1$. However, the losses of the PGTE $\left(l_{1}, l_{2}\right)$ are zero because its components rotate as a rigid body. Based on the previous discussion, the change in power flow pattern in the PGTE does not affect the total losses of the PGTE directly, but it leads to a jump in the power flow in the OGTE $\left(P_{5}\right)$, which in turn causes the jump in its losses $\left(l_{3}\right)$. The jump in $P_{5}$ is shown in Figure 13, the jump in $l_{3}$ is shown in Figure 12, and the jump in $l$ is shown in Figure 11 


\section{Conclusion}

In this work, a new method involving five topics of importance for studying the power losses and the efficiency of PGTs is discussed. First, a procedure for determining the succession of the angular velocities of any PGT is described, based on which the succession of the relative angular velocities can be obtained. Second, the speed sequence is used to determine the proper torque direction for any three active links of the PGT. Third, the input and output links can be determined in the carrier MRF based on torque directions and relative velocities. Fourth, the powers flowing through any three active links of the PGT are obtained in terms of the speed ratios and the efficiencies of the GPs from a single equation. Fifth, the losses calculated in the carrier MRF are used to formulate the total efficiency. The analysis techniques presented here are general to most gearing sets where power, power loss, and efficiency are the factors to be studied. To illustrate the application of the principles discussed, a representative two-input PGT is analyzed. The simplicity of techniques is particularly useful in analyzing power recirculation or amplification in complex PGTs.

To validate the theoretical results experimentally, the current results are compared with the experimental data of a previous work. The theoretical and experimental curves exhibit identical trends. There is a distinctive jump in the friction losses when the range of the input velocity ratio changes from $k<1$ to $k>1$. In fact, the jump is due to the change in the power flow pattern in the PGTE. The change in power flow pattern in the PGTE does not affect the total losses of the PGTE directly, but it leads to a jump in the power flow in the OGTE, which in turn causes the jump in its losses.

\section{Nomenclature}

$\begin{array}{ll}\text { PGT: } & \text { Planetary gear train } \\ \text { Two-DOF: } & \text { Two degrees of freedom } \\ \text { GPE: } & \text { Gear pair entity } \\ \text { GTE: } & \text { Gear train entity } \\ \text { GP: } & \text { Gear pair } \\ \text { PGTE: } & \text { Planetary gear train entity } \\ \text { OGTE: } & \text { Ordinary gear train entity } \\ \text { MRF: } & \text { Moving reference frame } \\ \text { FRF: } & \text { Fixed reference frame } \\ \eta_{c(x \rightarrow y)}: & \text { Mechanical efficiency of the GPE when operat- } \\ & \text { ing with a fixed carrier with link } x \text { as input and } \\ R_{q, p}^{c}: & \text { link } y \text { as output link } \\ P_{i}^{j}: & \text { Planet gear ratio } \\ R_{i, j}^{k}: & \text { Potential power that can be developed in gear } i \\ T_{i}: & \text { when link } j \text { is relatively fixed } \\ P_{\text {in }}: & \text { Velocity ratio between links } i \text { and } j \text { with respect } \\ P_{\text {out }}: & \text { to link } k \\ Z_{i}: & \text { External torque acting on link } i \\ \omega_{i}: & \text { Total input power } \\ l: & \text { Total output power } \\ & \text { Number of teeth on gear } i \\ & \text { Angular speed of gear } i \\ & \text { Overall tooth friction loss }\end{array}$

$\eta_{p}: \quad$ Planetary (epicyclic) gear train efficiency

$l i$ : $\quad$ Local tooth friction loss

$\eta_{(x, y \rightarrow z)}$ : $\quad$ Mechanical efficiency of the PGT when links $x$ and $y$ are input links and link $z$ is output link

$\eta_{c}: \quad$ Conventional gear train efficiency

$\xi$ : $\quad$ Tooth friction loss coefficient.

\section{Data Availability}

The data used to support the findings of this study are available from the corresponding author upon request.

\section{Conflicts of Interest}

The authors declare that they have no conflicts of interest.

\section{References}

[1] G. White, "Epicyclic gears from early hoists and winches-II," Mechanism and Machine Theory, vol. 29, no. 2, pp. 309-325, 1994.

[2] J. J. Park, B. S. Kim, and J. B. Song, "Double actuator unit with planetary gear train for a safe manipulator," in IEEE International Conference on Robotics and Automation, pp. 10-14, Italy, 2007.

[3] D. Rabindran and D. Tesar, "Power flow analysis in parallel force/velocity actuators_PFVA_: theory and simulations," in ASME International Design Engineering Technical Conferences and Computers and Information in Engineering Conference, pp. 3-6, New York, 2008.

[4] F. Zhu, L. Chen, and C. Yin, "Scheme design and optimal selection for HEV planetary gear coupling mechanism," in Proceedings of the ASME International Design Engineering Technical Conferences and Computers and Information in Engineering Conference 2009, DETC2009, vol. 6, pp. 943-949, 2010.

[5] K. B. Sheu, "Analysis and evaluation of hybrid scooter transmission systems," Appl. Energy, vol. 84, no. 12, pp. 12891304, 2007.

[6] J. Kim, N. Kim, S. Hwang, Y. Hori, and H. Kim, "Motor control of input-split hybrid electric vehicles," International Journal of Automotive Technology, vol. 10, no. 6, pp. 733-742, 2009.

[7] J. Kim, J. Kang, W. Choi et al., "Control algorithm for a power split type hybrid electric vehicle," in SPEEDAM 2010, pp. 1575-1580, Pisa, Italy, June 2010.

[8] I. Barman and D. R. Flugrad, "Design of an epicyclic transmission for speed control of a turbine-generator system," in Flexible Mechanisms, Dynamics, and Analysis, American Society of Mechanical Engineers, vol. 47, pp. 497-504, Design Engineering Division (Publication) DE, New York, 1992.

[9] X. Zhao and P. Maißer, "A novel power splitting drive train for variable speed wind power generators," Renewable Energy, vol. 28, no. 13, pp. 2001-2011, 2003.

[10] E. Pennestri' and F. Freudenstein, "The mechanical efficiency of epicyclic gear trains," Journal of Mechanical Design, vol. 115, no. 3, pp. 645-651, 1993.

[11] G. White, "Derivation of high efficiency two-stage epicyclic gears," Mechanism and Machine Theory, vol. 38, no. 2, pp. 149-159, 2003. 
[12] E. I. Radzimovsky, "A simplified approach for determining tooth friction losses and efficiency of epicyclic gear drives," Machine Design, vol. 9, pp. 101-110, 1956.

[13] D. J. Sanger, "The determination of power flow in multiplepath transmission systems," Mechanism and Machine Theory, vol. 7, no. 1, pp. 103-109, 1972.

[14] R. H. Macmillan, "Power flow and loss in differential mechanisms," Journal of Mechanical Engineering Science, vol. 3, no. 1, pp. 37-41, 2006.

[15] E. L. Esmail and S. S. Hassan, "An approach to power-flow and static force analysis in multi-input multi-output epicyclic-type transmission trains," Transactions of the ASME Journal of Mechanical Design, vol. 132, no. 1, 2010.

[16] H. Laughlin, A. Holowenko, and A. Hall, "How to determine circulating power in controlled epicyclic gear systems," Machine Design, vol. 28, no. 6, 1956.

[17] R. H. Macmillan and P. B. Davies, "Analytical study of systems for bifurcated power transmission," Journal of Mechanical Engineering Science, vol. 7, no. 1, pp. 40-47, 2006.

[18] H. I. Hsieh and L. W. Tsai, "The selection of a most efficient clutching Sequence associated with automatic transmission Mechanisms," ASME Journal of Mechanical Design, vol. 120, no. 4, pp. 514-519, 1998.

[19] Q. H. Duan and S. R. Yang, "A study on power flow and meshing efficiency of 3K type epicyclic gear train," Mechanical Science and Technology, vol. 21, no. 3, pp. 360-362, 2002.

[20] L.-C. Hsieh and T. H. Chen, "The design and efficiency analysis of Planetary gear reducer," Journal of Advanced Materials Research, vol. 317-319, pp. 2226-2229, 2011.

[21] E. L. Esmail, "Hybrid transmission for mobile robot," Journal of Mechanical Design, vol. 134, no. 2, article 021001, 2012.

[22] L. C. Hsieh and T. H. Chen, "On the meshing efficiency of $3 \mathrm{~K}-$ type Planetary simple gear reducer," Journal of Advanced Science Letters, vol. 12, no. 1, pp. 34-39, 2012.

[23] L.-C. Hsieh and H.-C. Tang, "On the meshing efficiency of $2 \mathrm{~K}-$ $2 \mathrm{H}$ type Planetary gear reducer," Advances in Mechanical Engineering, vol. 5, Article ID 686187, 2015.

[24] E. L. Esmail, "Meshing efficiency analysis of two degree-offreedom epicyclic gear trains," Journal of Mechanical Design, vol. 138, no. 8, 2016.

[25] E. L. Esmail, E. Pennestrì, and A. H. Juber, "Power losses in two-degrees-of-freedom planetary gear trains: a critical analysis of Radzimovsky's formulas," Mechanism and Machine Theory, vol. 128, no. 2, pp. 191-204, 2018.

[26] D. Yu and N. Beachley, "On the mechanical efficiency of differential gearing," Journal of Mechanisms, Transmissions, and Automation in Design, vol. 107, no. 1, pp. 61-67, 1985.

[27] C. Chen and J. Angeles, "Virtual-power flow and mechanical gear-mesh power losses of epicyclic gear trains," Journal of Mechanical Design, vol. 129, no. 1, pp. 107-113, 2007.

[28] C. Chen and T. T. Liang, "Theoretic study of efficiency of twodofs of epicyclic gear transmission via virtual power," Journal of Mechanical Design, vol. 133, no. 3, article 031007, 2011.

[29] C. Chen, "Power analysis of epicyclic transmissions based on constraints," Journal of Mechanisms and Robotics, vol. 4, no. 4, article 041004, 2012.

[30] C. Chen, "Power flow and efficiency analysis of epicyclic gear transmission with split power," Mechanism and Machine Theory, vol. 59, pp. 96-106, 2013.

[31] E. L. Esmail, "Comments on (power flow and efficiency analysis of epicyclic gear transmission with split power), by C. Chen,
Mech. Mach. Theory 59 (2013) 96-106," Mechanism and Machine Theory, vol. 115, pp. 237-243, 2017.

[32] F. Verbelena, P. Defreynea, P. Sergeanta, and K. Stockman, Efficiency measurement strategy for a planetary gearbox with 2 degrees of freedom, EEMODS, Energy Efficiency in Motor Driven Systems, Proceedings, 2019, http://hdl.handle.net/ 1854/LU-8629126.।.

[33] C. Wang, "High power density design for planetary gear transmission system," Journal of Mechanical Engineering Science, vol. 233, no. 16, pp. 5647-5658, 2019.

[34] L. D. Webster, "Rotary drive mechanism accepts two inputs," NASA Tech Brief, vol. 11, no. 5, p. 63, 1987.

[35] C. Chen and J. Chen, "Efficiency analysis of two degrees of freedom epicyclic gear transmission and experimental validation," Mechanism and Machine Theory, vol. 87, pp. 115-130, 2015.

[36] E. L. Esmail, "Influence of the operating conditions of twodegree-of-freedom planetary gear trains on tooth friction losses," Journal of Mechanical Design, vol. 140, no. 5, 2018.

[37] K. Davies, C. Chen, and B. K. Chen, "Complete efficiency analysis of epicyclic gear train with two degrees of freedom," Journal of Mechanical Design, vol. 134, no. 7, p. 071006, 2012.

[38] A. Maggiore, "The efficiency of epicyclic two DOF gear trains," Atti I Congresso Nazionale di Meccanica Teorica ed Applicata, III, vol. 6585, 1971.

[39] R. Monastero, "The efficiency of series connected epicyclic gear trains," in Rivista Associazione Tecnica dell'Automobile (ATA), Torino, Italy, 1976, (in Italian).

[40] E. L. Esmail, "A universal kinematic analysis of geared mechanisms," Journal of the Brazilian Society of Mechanical Sciences and Engineering, vol. 39, no. 6, pp. 2253-2258, 2017.

[41] R. F. Handschuh and C. J. Kilmain, Efficiency of high-speed helical gear trains, Cleveland $\mathrm{OH}$ Glenn Research Center, NASA, 2003. 